\title{
INJECTABLE PHOSPHOPULLULAN-FUNCTIONALIZED CALCIUM-SILICATE CEMENT FOR PULP-TISSUE ENGINEERING. AN IN-VIVO AND EX-VIVO STUDY.
}

\section{ABSTRACT \\ Objectives}

To evaluate, by means of an ex-vivo human tooth-culture model and in-vivo minipig animal study, the pulpal inflammatory reaction and reparative dentin-formation capacity of an injectable phosphopullulan-based calcium-silicate cement (GC, Tokyo, Japan) upon pulp capping, this in comparison with the commercial reference material Biodentine (Septodont).

Methods

For the ex-vivo tooth model, 9 freshly-extracted teeth from 3 different patients were pulp-capped with the experimental biomaterial $(n=3)$, Biodentine $(n=3)$ or left uncapped (control; $n=3)$. The teeth were kept in fresh culture medium for 4 weeks and, upon fixation three-dimensional Micro-CT and histology were performed. For the in-vivo animal study, 40 teeth from 3 minipigs were exposed and pulp capped with the experimental biomaterial containing phosphopullulan $(n=24)$ or Biodentine $(n=16)$ for 7 or 70 days. The inflammatory reaction and the tissue-regenerative potential was qualitatively and semiquantitatively characterized using three-dimensional micro-CT and histology.

Results

Ex vivo, the treatment with the experimental phosphopullulan-based calcium-silicate cement and Biodentine stimulated the formation of fibrous tissue and mineralized foci. In vivo, early inflammatory reaction and regeneration of the pulp-tissue interface was promoted by both bioceramic materials after 7 and 70 days, respectively.

Significance

Our findings bring new insights into calcium-silicate-mediated dental pulp repair and regeneration. The novel ready-to-use and self-adhering functionalized calcium-silicate cement revealed effective pulpal repair potential.

Keywords: Tissue regeneration; Calcium-silicate cements; Pulpal repair; Phosphopullulan; Biodentine; Animal model 


\section{Introduction}

Until recently, calcium hydroxide $(\mathrm{CaOH})$ has been considered the gold-standard material for pulp capping [1-3]. Although the body of evidence is still not strong enough, many clinicians and researchers have shifted to the more recently introduced hydraulic calcium-silicate cements (hCSCs) $[4,5]$. Some of its superior characteristics, as compared to $\mathrm{CaOH}$, are lower solubility and better sealing capacity together with a lower cytotoxicity towards human dental pulp cells (hDPCs), making hCSC the best candidate to take over the gold-standard label of $\mathrm{CaOH}$ for vital pulp therapy [5-8].

However, hCSCs fall short of the ideal characteristics a pulp-capping material should possess $[4,9]$. In particular, their difficult handling properties and the reported lack of adhesion to hard dental tissues trigger university and industrial researchers to further improve hCSC material technology [10-13]. To overcome some of these drawbacks, Biodentine (Septodont, Saint Maur des Fosses, France), a resinfree hCSC, was introduced in 2008 [14]. Initial research showed that the material is not cytotoxic against hDPCs and induces thick osteodentin bridge formation in in-vivo studies [15-17]. Moreover, its shorter setting time and reduced risk on discoloration make the product very popular among clinicians. However, Biodentine (Septodont) remains relatively difficult to handle, it does not adhere well to hard dental tissues and its long-term in-vivo efficacy as pulp-capping treatment is not yet known.

To solve some of the issues of hCSCs, particularly the lack of adhesion to hard dental tissues along with the difficult handling properties, a phosphopullulan-functionalized hydraulic calcium-silicate biomaterial (hCSC_PPL) has been developed. The main characteristic of this recently developed material consists of the addition of phosphorylated pullulan to its composition (Fig. 1) [18,19]. Pullulan is a non-toxic, non-mutagenic, non-carcinogenic biodegradable substance that has been used in the food, pharmaceutical and medical industries for a long time [20]. The synthesis of phosphopullulan is obtained by phosphorylation of pullulan, obtaining a colorless, odorless, edible and biodegradable powder $[18,21]$. By adding phosphorylated pullulan (PPL) to the calcium-silicate formulation, improved adhesion to tooth tissue has been strived for, like hCSC_PPL was documented to adhere to bony tissues $[22,23]$. Moreover, the biomaterial is provided in a ready-to-use capsule system, which guarantees easier and faster handling.

Animal models are the ultimate test for testing pulp-capping agents, but the pulp-tissue reaction when exposed to materials is not necessarily the same as that recorded in humans [24]. In this way, an ex-vivo human tooth-culture model was proposed $[25,26]$, hereby also providing means to reduce animal experimentation. The materials can be applied as done clinically, while the pulp cells remain within their natural environment and can function in almost similar physiological conditions as those in the human body. Nonetheless, this model can also be criticized as it lacks the immune and vascular systems of the patient. On the other hand, the ex-vivo human tooth-culture model can be seen as an 
improved cell-culture model, where the original 3D scaffold is involved and tooth pulps are capped following common clinical procedures. Even if the tooth model cannot fully replace animal experimentation, which probably will remain to serve as ultimate test prior to in-vivo human use, it can, when validated, serve as a screening tool to evaluate new pulp-capping formulations in a cheaper and faster manner with a reproducibility that may be higher than that of animal models.

The principal aim of this ex-vivo human tooth-culture model and in-vivo minipig animal study was to evaluate the pulpal inflammatory reaction and reparative dentin-formation capacity of the new injectable phosphopullulan-functionalized biomaterial (GC, Tokyo, Japan) upon pulp capping, this in comparison with the commercial reference material Biodentine (Septodont). The null-hypotheses tested were (1) that the new phosphopullulan-based hCSC (PPL_hCSC) does not provoke any kind of tissue reaction after $4 \mathrm{wk}$ pulp-capping in the ex-vivo human tooth-culture model, and (2) that PPL_hCSC does not induce pulpal inflammation or reparative dentin formation in vivo in the minipig model at 7 and 70 days, respectively.

\section{Materials and methods}

\subsection{Ex-vivo human tooth-culture model}

\subsubsection{Teeth sampling and culturing}

The samples were gathered after approval by the Commission for Medical Ethics of KU Leuven (file number S54254) and following informed consent from the donors. Fully impacted human third molars with their roots only partially formed, were collected immediately after extraction from three healthy young patients (15-17 years). A total of 9 teeth were used in this experiment. In the surgery room, the teeth were placed immediately after extraction in $50 \mathrm{ml}$ centrifuge tubes (VWR, Leuven, Belgium), containing Dulbecco's Modified Eagle Medium (DMEM; Gibco, Merelbeke, Belgium) supplemented with $10 \%$ Fetal Bovine Serum (FBS; Gibco), 1\% penicillin-streptomycin (Gibco) and 1\% amphotericin B (Gibco) (tooth-culture medium). The samples were brought to the cell-culture room within $4 \mathrm{~h}$ to proceed with the cell-culture experiments. From each patient, one tooth was kept as negative control ( $n=3$; exposure without capping), while the other teeth were capped with PPL_hCSC $(n=3)$ or Biodentine $(n=3)$ and kept in tooth-culture medium for $4 w k$, as described below.

Once in the cell-culture room, all teeth were rinsed with 70\% ethanol (Hydral 70, VWR) for 1 min, followed by rinsing with sterile Phosphate Buffered Saline (PBS; Sigma Aldrich, St. Louis, MO, USA) for $1 \mathrm{~min}$, upon which they were then placed in tooth-culture medium until further processed. The periodontal ligament was removed with a sterile \#15 scalpel blade (Swann Morton, Sheffield, UK). After cleaning, the teeth were handled with sterile gauzes (Yibon Medical, Kuurne, Belgium) and 
soaked in tooth-culture medium to avoid desiccation.

\subsubsection{Ex-vivo human tooth-culture pulp-capping assay}

Nine teeth from three different patients were gathered and handled as described above. Once the teeth were cleaned, a pulp-capping procedure was performed in sterile conditions and with the aid of $2.8 \mathrm{x}$ magnification, similarly as done clinically. For the pulp-capping assay, we followed the protocol described by Téclès et al. 2005 [25]. Briefly, a class-I cavity (approx. 4×4×4 mm) was cut using a sterile bur (1.1 mm in diameter; Endo Access Bur Size 1, A 0164300001 00, Dentsply Sirona, Ballaigues, Switzerland) at high speed under copious irrigation with sterile saline (Fresenius Kabi, Bad Homburg, Germany). The pulp was exposed with a round carbide bur (1.0 mm in diameter; H1SE.205.010, Komet, Lemgo, Germany) at low speed with abundant irrigation. Afterwards, the cavity was cleaned with sterile saline and gently dried with sterile cotton pellets.

The teeth were divided into three groups depending on the pulp-capping procedure carried out: (1) application of the experimental phosphopullulan-functionalized hCSC '(PPL_hCSC'; n=3; GC), (2) application of the commercial hCSC Biodentine ( $n=3$; Septodont), or (3) exposure without capping as negative control $(n=3)$. The composition and application mode of the two pulp-tissue engineering agents investigated are detailed in Table 1.

PPL_hCSC and Biodentine were applied in a 2-3 mm layer following the manufacturers' recommendations and gently compacted with sterile cotton pellets. The cavity was restored with glassionomer cement (Fuji II LC Capsules, GC). Next, flowable composite (G-aenial Flo, GC) was applied on the occlusal surface, in which a sterilized stainless steel orthodontic wire ( $M$ form; ORMCO, Orange, CA, USA) was seated, followed by 40 -sec light-curing of the flowable composite using a light-curing unit with a light output of $1200 \mathrm{~mW} / \mathrm{cm}^{2}$ (Bluephase 20i, Ivoclar Vivadent, Schaan, Liechtenstein). The teeth were immediately hanged using the wire in separate wells of 24-well culture plates (Costar, Cambridge, MA, USA), each containing $1.5 \mathrm{ml}$ of tooth-culture medium to ensure generous exposure of the pulp tissue to the medium. The medium was refreshed every day and after four weeks the wire was removed and the teeth immediately placed in 4\% PFA for two weeks to properly fix the tissue.

\subsubsection{Ex-vivo human tooth-culture model - histology}

The chemically fixed teeth were demineralized (4-6 weeks) with $10 \%$ formic acid (Chem-Lab Analytical, Zedelgem, Belgium) with the decalcifying solution refreshed every 3 days. The decalcification endpoint was determined by dental radiography (MINRAY, Soredex, Tuusula, Finland) and visual/tactile evaluation. After decalcification, the glass ionomer and composite restorations were manually removed, upon which the teeth were subsequently immersed in water for $24 \mathrm{~h}$ and then dehydrated 
in ascending concentrations of ethanol ( $70 \%$ for $12 \mathrm{~h}, 80 \%, 95 \%$ and $100 \%$ for $2 \mathrm{~h}$ each), followed by xylene (VWR) clearance. The teeth were next immersed in liquid paraffin $\left(56^{\circ} \mathrm{C}\right.$ melting point; Paraclean, Klinipath, Duiven, The Netherlands) for $24 \mathrm{~h}$ prior to being embedded in paraffin blocks. Serial paraffin sections were cut with a thickness of 5-7 $\mu \mathrm{m}$ using a microtome (Microm HM 360 Microtome, Hyland Scientific, Stanwood, WA, USA), this from the level where the interaction of the pulp-capping agent and the pulp tissue first appeared until any interaction was no longer visible. Every six sequential sections, two sections were randomly selected for staining. One section was stained with Gill's III hematoxylin (Leica Microsystems, Diegem, Belgium) and with 1\% aqueous eosin solution (Leica Microsystems), while the other section was stained with Gram-Twort staining to detect the presence of bacteria. The stained sections were examined using light microscopy (Axio Imager M2, Carl Zeiss Microscopy, Jena, Germany). The formation/presence of a fibrous band and mineralized tissue around the exposed area was evaluated by two independent researchers.

\subsection{Animal experimentation}

\subsubsection{Minipigs}

All experimental protocols complied with the ARRIVE guidelines and were approved by the Ethical Committee for Animal Experimentation of KU Leuven under the file number P016/2015. The procedures were carried out in accordance with the UK Animals (Scientific Procedures) Act 1986 and EU Directive 2010/63/EU for animal experiments. Three female Göttingen minipigs (Ellegaard, Dalmose, Denmark) at the age of 33-35 months and with a weight of 44-60 kg and intact permanent dentitions were group-housed on wood shavings with ad libitum access to water; they were fed twice a day with a minipig special diet (Welzijnskorrelminivarkens, AVEVE, Wilsele, Belgium).

\subsubsection{Direct pulp capping}

A pre-operative computed tomography (CT) scan (SOMATOM Force, Siemens Healthcare, Erlangen, Germany) of the mandible and maxilla of each minipig was taken in order to confirm that all teeth were in a healthy state and the roots were fully developed. Direct pulp capping was carried out at two times, resulting in a 7-day and 70-day post-operative observation period, as recommended by the ISO 7045-2008 standard [27]. Twenty permanent teeth (5 incisors, 2 canines, 8 premolars and 5 molars) on the left side were capped in the first phase (70-day post-capping observation). Sixty-three days later, 20 permanent teeth ( 7 incisors, 2 canines, 6 premolars and 5 molars) on the right side received a pulp-capping treatment (7-day post-capping observation).

Animals were anesthetized with a combination of xylazine $(1 \mathrm{mg} / \mathrm{kg} ; 2 \% \mathrm{Xyl}-\mathrm{M}, \mathrm{VMD}$, Arendonk, Belgium) and zolazepam/tiletamine (2.5-3 mg/kg; Zoletil 100, Virbac, Fort Worth, TX, USA). After 
endotracheal intubation, general anesthesia was maintained with isoflurane (1-1.5\%); then, the animals were ventilated with a tidal volume of $8-10 \mathrm{ml} / \mathrm{kg}$ at a frequency of $10-12$ times per min to preserve normocapnea. Prior to direct pulp capping, the teeth were ultrasonically cleaned (MiniMaster Ultrasonic Scaler; Electro Medical Systems (EMS), Nyon, Switzerland), polished, and disinfected with $10 \%$ povidone iodine (iso-Betadine Dermicum, Meda Pharma, Belgium). Under local anesthesia using $2 \%$ lidocaine $(1 \mathrm{ml}$ per tooth), class- $\mathrm{V}$ butt-joint cavities were prepared on the buccal surface of incisors, canines and premolars, whereas class-I cavities were cut on the occlusal surface of molars. The cavities were prepared using a sterile round diamond bur (1.1 mm in diameter; Endo Access Bur size 1, Dentsply Sirona) at ultra-high speed with copious sterile saline irrigation. Subsequently, the pulp tissue was mechanically exposed using a sterile round carbide bur (1.0 mm in diameter; H1SE.205.010, Komet) mounted on a dental hand-piece at high speed under sterile saline (Fresenius Kabi) cooling. The cavities were rinsed with sterile saline (Fresenius Kabi) and hemorrhage was controlled using sterile wet cotton pellets with light pressure, upon which the cavities were dried with sterile dry cotton pellets.

All teeth receiving pulp-capping treatment were randomly divided into 2 groups. For PPL_hCSC, 12 teeth consisting of 3 incisors, 1 canine, 5 premolars and 3 molars were selected. For the commercial reference cement Biodentine (Septodont), 8 teeth ( 2 incisors, 1 canine, 3 premolars and 2 molars) were chosen. The pulp-capping agents were applied with a thickness of approximately $2 \mathrm{~mm}$. PPL_hCSC was prepared by activating the capsule followed by mixing for $10 \mathrm{sec}$ with a capsule mixer (RotoMix Capsule Mixer, 3M Oral Care, Seefeld, Germany). For Biodentine (Septodont), 5 drops of liquid were added to the powder capsule, upon which the capsule was immediately mixed for $30 \mathrm{sec}$ with the mixer (Rotomix, 3M Oral Care). Once the pulp-capping agents were placed following the manufacturers' recommendations and gently compacted with sterile cotton pellets, a layer of resinbased glass-ionomer cement (Fuji II LC Capsule, GC) was applied. The cavities were finally restored with a universal adhesive (G-Premio Bond, GC) and a light-curing composite (G-aenial Posterior, GC). During restorative procedures, humidity was controlled with sterile cotton rolls in combination with oral suction. Soft diet was provided post-operatively and no anti-inflammatory medication appeared necessary for any of the three animals.

Sixty-three days after the first phase, the same dental procedures were performed in the teeth on the right side. The animals were euthanized 7 days after the second phase using an overdose of barbiturates (400 mg/ml; Euthasol, Le Vet, Oudewater, The Netherlands). The mandible and maxilla were simultaneously fixed by immersion in $4 \%$ paraformaldehyde solution (VWR) via a closed headonly perfusion system with inflow through the carotid artery and outflow via the jugular vein [28]. The teeth were removed individually from the jaw using an electric saw (HB 8894, HEBU Medical, Tuttlingen, Germany) under copious water irrigation and afterwards immediately fixed in $30 \mathrm{ml}$ of $4 \%$ 
paraformaldehyde solution (VWR) at $4^{\circ} \mathrm{C}$ for 2 weeks.

\subsubsection{Micro-computed tomography $(\mu \mathrm{CT})$}

All teeth were scanned by means of a $\mu \mathrm{CT}$ scanner (Skyscan 1172, Bruker MicroCT, Kontich, Belgium) using the following parameters: $100 \mathrm{kV} / 100 \mu \mathrm{A}$ X-ray source, $0.5 \mathrm{~mm}$ aluminum filter, pixel size of 9.92 $\mu \mathrm{m}$, averaging frame of 7 , rotation step of $0.3^{\circ}$, random movement of 50 and $360^{\circ}$ rotation around the vertical axis. The raw data were reconstructed using NRecon v.1.6.9.18 software (Bruker MicroCT), using the same parameters for smoothing, beam hardening and ring artifact corrections.

\subsubsection{Continuity of mineralized tissue}

For exposed pulps capped for 70 days, the presence of radiodensity change in the pulp tissue was qualitatively documented using the Dataviewer software v. 1.5.1.2 (Bruker MicroCT). The radiopaque layer underneath the exposure site, if existed, was further identified as mineralized tissue or not, this using the corresponding histology of the teeth as a reference. The continuity of mineralized tissue was classified as 'none', 'partial' or 'complete', based on the extent of mineralized tissue compared to that of the exposure site.

\subsubsection{Three-dimensional bridge segmentation and porosity analysis}

We used CTAn v.1.13 software (Bruker MicroCT) to define different volumes of interest (VOIs) for each structural feature (dentin, dentin bridge and pulp tissue/pores) by manual definition of the regions of interest (ROIs) using the full-axial slices dataset. Dataviewer software and the corresponding histology were used as support references. An automatic thresholding method (Otsu 2D) was applied for segmenting dentin and the dentin bridge from the pulp tissue/pores. CTVox software (Bruker MicroCT) was used to render the volume and to merge the different structural features on the 3D models.

\subsubsection{Animal experimentation - histology}

After $\mu \mathrm{CT}$ scanning, the chemically fixed teeth were processed for paraffin-section histology and evaluated using light microscopy (Axio Imager M2, Carl Zeiss Microscopy), as described above for the ex-vivo human tooth-culture pulp-capping assay. The inflammatory response of the exposed pulp as well as the nature of newly formed mineralized tissue were evaluated based on the criteria detailed below.

\subsubsection{Inflammatory response}

The grade of inflammatory response in the pulp tissue, being capped with each pulp-capping agent, 
was calculated according to the grading scale of inflammatory changes described in the ISO 7045-2008 standard [27]:

GRADE 0: no inflammation;

GRADE 1: mild inflammation - scattered inflammatory cells in the pulp tissue adjacent to the pulp exposure;

GRADE 2: moderate inflammation - inflammatory cells with small focal groupings in the pulp tissue adjacent to the pulp exposure;

GRADE 3: severe inflammation - extensive inflammatory cell infiltration in the pulp tissue adjacent to the pulp exposure;

GRADE 4: abscess formation or extended inflammatory cell infiltration not only limited to the pulp tissue adjacent to the pulp exposure.

\subsubsection{Nature of mineralized tissue}

The formation/continuity of mineralized tissue was previously assessed by $\mu \mathrm{CT}$. The nature of mineralized tissue was defined as either 'immature', 'maturing' or 'mature' on basis of the presence of reparative dentin with well-aligned dentin tubules as well as a layer of well-arranged odontoblastlike cells.

\subsubsection{Bacterial staining}

Gram-Twort staining was performed for bacterial recognition.

\subsection{Statistical analysis}

For the presence of mineralized tissue in the ex-vivo human tooth-culture model among the three different groups, the non-parametric Kruskal-Wallis test was used (Bonferroni correction applied), this at a significance level of $p<0.05$. The occurrence of inflammatory response as well as mineralized tissue formation induced by the different pulp-capping agents in vivo were evaluated by two independent observers. In case of disagreement, re-evaluation was done and the more severe evaluation was chosen. The data were statistically compared using the Fisher's Exact test or Chi-square test of independence, this at a significance level of $p<0.05$.

\section{Results}

\subsection{Ex-vivo human tooth-culture model - histology}

All teeth capped with both hCSCs revealed the presence of mineral foci around the exposure area after 
4 weeks (Table 2). Representative histology micrographs of teeth capped by PPL_hCSC and Biodentine can be seen in Figure 2a-d. Both materials stimulated the formation of mineral structures around the exposure site, which would lead to the future formation of a mineralized bridge covering/healing the exposed region. At higher magnification, the area immediately adjacent to the pulp exposure appeared rich in fibrinous tissue and mineral foci. When the teeth remained uncapped (control), no mineral tissue formation, nor fibrinous tissue reaction was observed around the exposed area (Figure 2e,f; Table 2).

\subsection{Minipig animal experimentation}

\subsubsection{Micro-computed tomography $(\mu \mathrm{CT})$}

\subsubsection{Radiodensity change in exposed pulps}

All teeth capped by both hCSCs revealed a radiopaque zone around the exposure area after 7 and 70 days. Representative reconstructed $\mu \mathrm{CT}$ images of teeth capped by PPL_hCSC and Biodentine can be seen in Figure 3 along with their corresponding histological micrographs. Histology confirmed that the radiopaque zone stained more eosinophilically than the deeper pulp tissue (Figure 3b,f). At higher magnification, the area immediately adjacent to the pulp exposure appeared richer in cells, collagen fibrils and capillaries (Figure $3 c, d$ ).

\subsubsection{Continuity of mineralized tissue}

Using the histology as reference, the radiopaque zone observed in the exposed pulps capped for 70 days was characterized as mineralized tissue. The continuity of mineralized tissue induced by the different pulp-capping hCSCs is summarized in Table 3. For both hCSCs investigated, the continuity of mineralized tissue was judged as 'complete' for all capped teeth (100\%), indicating that the whole exposure site was completely sealed (Table 3 ).

\subsubsection{Three-dimensional bridge segmentation and porosity analyses}

For both hCSCs investigated, continuous bridge structures were visualized by $\mu \mathrm{CT}$. Clear pores were detected in the young bridges, however without direct contact between hCSC and pulp; hence, no tunnel defects were found. One representative specimen of each hCSC is documented in Figure 4.

\subsubsection{Histology}

\subsubsection{Inflammatory response}

The inflammatory response generated by both hCSCs is summarized in Table 4. Overall, there was no difference regarding inflammatory reaction provoked by the two pulp-capping agents investigated. 
Histological micrographs of six representative teeth that were capped by PPL_hCSC and Biodentine (Septodont) for 7 days (including a representative control tooth) are shown in Figures 3, 5 and 6. Most specimens evaluated 7 days after pulp capping were rated with inflammatory grades 1 or 2 . Scattered inflammatory cells or inflammatory cells with small focal grouping were detected in the area next to the exposure site. The pulp tissue immediately adjacent to the exposure appeared richer in cells and collagen fibrils. Moreover, in some cases, the presence of prominent capillaries could be observed in the matrix, this for both hCSCs investigated. These results confirmed the findings obtained with the exvivo human tooth-culture model.

\subsubsection{Nature of the mineralized tissue}

The nature of the mineralized tissue formed is detailed in Table 5. For all the specimens capped with PPL-hCSC (GC) or Biodentine (Septodont) for 7 days, no clear mineralized tissue was formed, while after 70 days, the formation of a thick mineralized bridge was observed in all specimens. Histological micrographs of two representative specimens capped with PPL_hCSC (GC) and Biodentine (Septodont) are shown in Figure 7. In both specimens, a thick $(200-500 \mu \mathrm{m})$ osteodentin bridge was formed. The area of the mineralized bridge next to the $\mathrm{hCSC}$ is composed of a disorganized pattern of mineralization without or only with scarce and irregular tubules. On the other hand, the part of the bridge facing the pulpal tissue is composed of a better organized tissue, in which dentin tubules can clearly be detected. A layer of odontoblast-like cells aligning below the mineralized structure was observed.

\subsubsection{Bacterial staining}

No bacterial contamination was detected at the cavity floor wall or within the pulp tissue of any of the specimens studied.

\section{Discussion}

Overall, this study proved that the injectable phosphopullulan-functionalized biomaterial stimulated the formation of fibrinous tissue and mineral foci when PPL_hCSC made contact with exposed pulp tissue. Therefore, the first null-hypothesis that the new phosphopullulan-based hCSC (PPL_hCSC) does not provoke any kind of tissue reaction after 4 wk pulp-capping in the ex-vivo human tooth-culture model was rejected. Moreover, PPL_hCSC stimulates pulpal inflammation and reparative dentin formation at a similar extent as the commercial hCSC Biodentine (Septodont) in a minipig animal model after 7 and 70 days. Therefore, the second null-hypothesis that that PPL_hCSC does not induce pulpal inflammation or reparative dentin formation in vivo in the minipig model at 7 and 70 days, respectively was also rejected.

Well-controlled randomized clinical trials provide hard evidence of clinical effectiveness. However, 
before any pulp-capping agent can reach the stage of clinical testing in humans, it is desirable that it successfully passes in-vitro and in-vivo animal studies to demonstrate its safety of use. In a previous invitro study, we showed that PPL_hCSC is not cytotoxic against hDPCs and also stimulates migration, proliferation and odontogenic differentiation of hDPCs [15]. In a next phase, using an ex-vivo human tooth-culture model, we could confirm that PPL_hCSC provoked a positive reaction in human dental pulps. Fully aware of the ethical concerns related to animal studies, the minipig study was conducted upon successfully passing the previous cell-culture experiments, while evaluating the response of a living pulp to a new pulp-capping agent is still believed mandatory prior to initiating a clinical trial in humans. A Göttingen mini-pig model was selected for many reasons. Compared with small animal models, such as rodents, large animal models are superior in many aspects to study diseases and preclinical therapies [29]. Regarding other large animal models, like baboons or dogs, minipigs have been documented to possess dental and pulpal tissue anatomies and physiologies that are very similar to those of humans [29]. Moreover, having 44 permanent teeth, the minipig model allows comparing different materials at the same time using a split-mouth design in a limited number of animals.

The use of the human tooth-culture model for the study of the early stages of pulp-tissue reaction after pulp capping was already used in the past $[25,26,30]$. However, the number of publications using this model is scarce and they originate from the same research group. In recent previous research we validated the human tooth-culture model by investigating the growth efficiency, expression of mesenchymal stem cell markers and differentiation ability of hDPCs [31]. Even though in vivo animal experimentation provides harder evidence as compared with the ex-vivo human tooth-culture model, this study confirmed that the use of this ex-vivo model can be a valuable screening tool to investigate the early episodes after pulp exposure and capping before animal testing is conducted.

After any kind of pulpal trauma, inflammation is a natural consequence as a defense mechanism. Inflammation has a controverted effect on pulp regeneration and repair [32-34]. While some authors in the past argued that inflammation had solely a negative effect due to the risk on pulp necrosis, more recently other authors argued that inflammation has a positive and necessary role in tissue repair [35]. This positive effect is thought to be promoted by the role of different growth factors (among others, TGF- $\beta 1$ ) and cytokines [35]. Therefore, any kind of material meant to be directly exposed to pulp tissue should be able to maintain the inflammatory reaction to the minimum, not passing beyond the stage that will lead to pulp necrosis. Calcium-silicate cements have already demonstrated to stimulate the release of growth factors and cytokines when in contact with hDPCs [36-38]. In our study, 11 out of 12 teeth (91.6\%) exposed to PPL_hCSC showed mild to moderate inflammation. This is comparable to the 7 out of 8 teeth (87.5\%) that were exposed to Biodentine (Septodont) and also revealed mild to moderate inflammation. In this sense, our results confirm that the phosphopullulan-functionalized biomaterial is a safe option for pulp-tissue engineering procedures. 
In the long term, the formation of a homogenous, thick and continuous mineralized bridge seems to be a necessity for a successful pulp-capping treatment [39]. Previous research has shown that the main reasons for failure after pulp capping with $\mathrm{CaOH}$ are the presence of tunnel defects in the bridge formed and also the dissolution of $\mathrm{CaOH}$ over time [39]. Our results showed that PPL-hCSC seems promising in terms of reparative dentin formation after a period of 10 weeks. A complete bridge was observed in $100 \%$ of the PPL_hCSC- and Biodentine-capped teeth, with $100 \%$ of the specimens showing maturing or even mature bridges. Reparative dentin formed was in most cases thick, continuous and homogeneous, similar to those formed after capping with Biodentine (Septodont) and this after a relatively short period of time. However, the results of this in-vivo animal study should be taken with care due to the fact that all the capping procedures were performed in healthy caries-free teeth of healthy animals. It has already been shown in literature that the characteristics of the reparative bridge formed after pulp-capping procedures in healthy teeth in animals are not exactly the same as those occurring in human teeth affected by deep caries [24].

In our study, two bioceramic materials have been tested ex vivo and in vivo for pulp-tissue regeneration and repair. The experimental injectable phosphopullulan-functionalized biomaterial has previously shown high calcium release and the establishment of a high $\mathrm{pH}$ in the tissues, on which the material is applied $[22,40]$. After pulp injury, dental pulp stem cells have been demonstrated to play a key role in the regeneration and repair of the defect $[41,42]$. In this sense, calcium (Ca) and silicon (Si) release have widely been shown to be a key factor in order to stimulate migration, proliferation and differentiation of human stem cells $[43,44]$. Moreover, Ca and Si have also been shown to play an important role in osteoblast proliferation and collagen production [45]. Therefore, it seems that the stimulation of a bacteria-free environment together with a high calcium and silicon release may be potential explanations for the formation of mineral foci in the ex-vivo study as well as the pulp regeneration and repair in the in-vivo animal study.

\section{Conclusion}

Many different animal models have been recommended for pulp-capping studies. However, minipigs seem to be an excellent option due to their genetic and anatomic similarities with humans.

A phosphopullulan-functionalized biomaterial, delivered in a handy capsule system, appeared promising for pulp-tissue engineering and potentially also for other root repair-related applications. The ex-vivo part of this study showed similar favorable pulp-tissue reactions with both biomaterials. Moreover, the in-vivo study did not reveal differences in pulpal inflammation and reparative dentin formation induced by the two hCSCs investigated. Finally, well-controlled randomized clinical trials remain to be performed before any material can be recommended for routine use in patients. 


\section{Declaration of interest}

Prof. Yasuhiro Yoshida was involved in the development of phosphopullulan, for which a patent has been submitted.

\section{Acknowledgments}

MSP is appointed as PhD fellow ('Aspirant') of the Research Foundation - Flanders (FWO). This research was financed by the FWO research grant G.0893.15. We would like to thank Mr. Wilfried Versin and the Translational Cell and Tissue Research Department of the University Hospitals of Leuven (UZ Leuven) for their help with the histological sectioning and staining of the samples. We want to acknowledge all the staff members and assistants of the Department of Oral and Maxillofacial Surgery (MKA) for their help to collect freshly-extracted human third molars. We also want to appreciate the dental manufacturers Septodont and GC Europe for providing the pulp-capping materials.

\section{Data availability}

The raw/processed data required to reproduce these findings cannot be shared at this time due to technical or time limitations.

The data could be provided on a later moment on request. 


\section{References}

[1] Sangwan P, Sangwan A, Duhan J, Rohilla A. Tertiary dentinogenesis with calcium hydroxide: A review of proposed mechanisms. Int Endod J 2013;46:3-19. doi:10.1111/j.1365-2591.2012.02101.x.

[2] Chailertvanitkul P, Paphangkorakit J, Sooksantisakoonchai N, Pumas N, Pairojamornyoot $\mathrm{W}$, Leela-apiradee $\mathrm{N}$, et al. Randomized control trial comparing calcium hydroxide and mineral trioxide aggregate for partial pulpotomies in cariously exposed pulps of permanent molars. Int Endod J 2014;47:835-42. doi:10.1111/iej.12225.

[3] Mente J, Hufnagel S, Leo M, Michel A, Gehrig H, Panagidis D, et al. Treatment outcome of mineral trioxide aggregate or calcium hydroxide direct pulp capping: long-term results. J Endod 2014;40:1746-51. doi:10.1016/j.joen.2014.07.019.

[4] Zhu L, Yang J, Zhang J, Lei D, Xiao L, Cheng X, et al. In vitro and in vivo evaluation of a nanoparticulate bioceramic paste for dental pulp repair. Acta Biomater 2014;10:515668. doi:10.1016/J.ACTBIO.2014.08.014.

[5] Parirokh M, Torabinejad M, Dummer PMH. Mineral trioxide aggregate and other bioactive endodontic cements: an updated overview - part I: vital pulp therapy. Int Endod J 2018;51:177-205. doi:10.1111/iej.12841.

[6] Li H, Xue K, Kong N, Liu K, Chang J. Silicate bioceramics enhanced vascularization and osteogenesis through stimulating interactions between endothelia cells and bone marrow stromal cells. Biomaterials 2014;35:3803-18. doi:10.1016/J.BIOMATERIALS.2014.01.039.

[7] Li X, De Munck J, Yoshihara K, Pedano M, Van Landuyt K, Chen Z, et al. Re-mineralizing dentin using an experimental tricalcium silicate cement with biomimetic analogs. Dent Mater 2017;33:505-13. doi:10.1016/j.dental.2017.02.003.

[8] Li X, De Munck J, Van Landuyt K, Pedano M, Chen Z, Van Meerbeek B. How effectively do hydraulic calcium-silicate cements re-mineralize demineralized dentin. Dent Mater 2017;33:434-45. doi:10.1016/j.dental.2017.01.015.

[9] Anastasiadis K, Koulaouzidou EA, Palaghias G, Eliades G. Bonding of Composite to Base Materials: Effects of Adhesive Treatments on Base Surface Properties and Bond Strength. J Adhes Dent 2018;20:151-64. doi:10.3290/j.jad.a40302.

[10] Parirokh M, Torabinejad M. Mineral Trioxide Aggregate: A Comprehensive Literature 
Review-Part III: Clinical Applications, Drawbacks, and Mechanism of Action. J Endod 2010;36:400-13. doi:10.1016/j.joen.2009.09.009.

[11] Gandolfi MG, Taddei P, Siboni F, Modena E, Ciapetti G, Prati C. Development of the foremost light-curable calcium-silicate MTA cement as root-end in oral surgery. Chemical-physical properties, bioactivity and biological behavior. Dent Mater 2011;27:e134-57. doi:10.1016/j.dental.2011.03.011.

[12] Schmidt A, Schäfer E, Dammaschke T. Shear Bond Strength of Lining Materials to Calcium-silicate Cements at Different Time Intervals. J Adhes Dent 2017;19:129-35. doi:10.3290/j.jad.a38100.

[13] Torabinejad M, Parirokh M, Dummer PMH. Mineral trioxide aggregate and other bioactive endodontic cements: an updated overview - part II: other clinical applications and complications. Int Endod J 2018;51:284-317. doi:10.1111/iej.12843.

[14] Laurent P, Camps J, De Méo M, Déjou J, About I. Induction of specific cell responses to a Ca3SiO5-based posterior restorative material. Dent Mater 2008;24:1486-94. doi:10.1016/j.dental.2008.02.020.

[15] Pedano MS, Li X, Li S, Sun Z, Cokic SM, Putzeys E, et al. Freshly-mixed and setting calcium-silicate cements stimulate human dental pulp cells. Dent Mater 2018;34:797808. doi:10.1016/j.dental.2018.02.005.

[16] Li X, Pedano MS, Camargo B, Hauben E, De Vleeschauwer S, Chen Z, et al. Experimental tricalcium silicate cement induces reparative dentinogenesis. Dent Mater 2018;34:1410-23. doi:10.1016/j.dental.2018.06.016.

[17] Tran X-V, Gorin C, Willig C, Baroukh B, Pellat B, Decup F, et al. Effect of a Calciumsilicate-based Restorative Cement on Pulp Repair. J Dent Res 2012:1166-71. doi:10.1177/0022034512460833.

[18] Yoshida Y, Tanaka M, Suzuki K, Ozaki T, Takahata T, Irie M, et al. Kit for adhering biological hard tissues. US 9,186,433 B2, 2011.

[19] Yonehiro J, Yoshida Y, Yamashita A, Yoshizawa S, Ohta K, Kamata N, et al. Flavonolcontaining phosphorylated pullulan may attenuate pulp inflammation. Int Endod J 2013;46:119-27. doi:10.1111/j.1365-2591.2012.02095.x.

[20] Kimoto T, Shibuya T, Shiobara S. Safety studies of a novel starch, pullulan: Chronic toxicity in rats and bacterial mutagenicity. Food Chem Toxicol 1997;35:323-9. doi:10.1016/S0278-6915(97)00001-X. 
[21] Prajapati VD, Jani GK, Khanda SM. Pullulan: An exopolysaccharide and its various applications. Carbohydr Polym 2013;95:540-9. doi:10.1016/j.carbpol.2013.02.082.

[22] Cardoso M, Chaudhari A, Yoshihara K, Mesquita M, Yoshida Y, Van Meerbeek B, et al. Phosphorylated Pullulan Coating Enhances Titanium Implant Osseointegration in a Pig Model. Int J Oral Maxillofac Implants 2017;32:282-90. doi:10.11607/jomi.5074.

[23] Yoshida Y, Nagakane K, Fukuda R, Nakayama Y, Okazaki M, Shintani H, et al. Comparative study on adhesive performance of functional monomers. J Dent Res 2004;83:454-8.

[24] Emara R, Elhennawy K, Schwendicke F. Effects of calcium silicate cements on dental pulp cells: A systematic review. J Dent 2018;77:18-36. doi:10.1016/j.jdent.2018.08.003.

[25] Téclès O, Laurent P, Zygouritsas S, Burger AS, Camps J, Dejou J, et al. Activation of human dental pulp progenitor/stem cells in response to odontoblast injury. Arch Oral Biol 2005;50:103-8. doi:10.1016/j.archoralbio.2004.11.009.

[26] Téclès $O$, Laurent $P$, Aubut $V$, About I. Human tooth culture: A study model for reparative dentinogenesis and direct pulp capping materials biocompatibility. J Biomed Mater Res - Part B Appl Biomater 2008;85:180-7. doi:10.1002/jbm.b.30933.

[27] ISO 7405. Dentistry - Evaluation of biocompatibility of medical devices used in dentistry 2013.

[28] Musigazi GU, De Vleeschauwer S, Sciot R, Verbeken E, Depreitere B. Brain perfusion fixation in male pigs using a safer closed system. Lab Anim 2018;52:413-7. doi:10.1177/0023677217752747.

[29] Wang S, Liu Y, Fang D, Shi S. The miniature pig: A useful large animal model for dental and orofacial research. Oral Dis 2007;13:530-7. doi:10.1111/j.16010825.2006.01337.x.

[30] Laurent P, Camps J, About I. Biodentine(TM) induces TGF- $\beta 1$ release from human pulp cells and early dental pulp mineralization. Int Endod J 2012;45:439-48. doi:10.1111/j.1365-2591.2011.01995.x.

[31] Pedano MS, Li X, Jeanneau C, Ghosh M, Yoshihara K, Van Landuyt K, et al. Survival of Human Dental Pulp Cells After 4-Week Culture In Human Tooth Model. J Dent 2019. doi:10.1016/j.jdent.2019.05.023.

[32] Goldberg M, Farges JC, Lacerda-Pinheiro S, Six N, Jegat N, Decup F, et al. Inflammatory 
and immunological aspects of dental pulp repair. Pharmacol Res 2008;58:137-47. doi:10.1016/j.phrs.2008.05.013.

[33] About I. Dentin-pulp regeneration: the primordial role of the microenvironment and its modification by traumatic injuries and bioactive materials. Endod Top 2013;28:61-89. doi:10.1111/etp.12038.

[34] Goldberg M, Njeh A, Uzunoglu E. Is Pulp Inflammation a Prerequisite for Pulp Healing and Regeneration? Mediators Inflamm 2015;2015:1-11. doi:10.1155/2015/347649.

[35] Eming SA, Wynn TA, Martin P. Inflammation and metabolism in tissue repair and regeneration. Science (80- ) 2017;356:1026-30. doi:10.1126/science.aam7928.

[36] Giraud T, Rufas P, Chmilewsky F, Rombouts C, Dejou J, Jeanneau C, et al. Complement Activation by Pulp Capping Materials Plays a Significant Role in Both Inflammatory and Pulp Stem Cells' Recruitment. J Endod 2017;43:1104-10. doi:10.1016/j.joen.2017.02.016.

[37] Giraud T, Jeanneau C, Rombouts C, Bakhtiar H, Laurent P, About I. Pulp capping materials modulate the balance between inflammation and regeneration. Dent Mater 2019;35:24-35. doi:10.1016/j.dental.2018.09.008.

[38] Sanz J, Rodríguez-Lozano F, Llena C, Sauro S, Forner L. Bioactivity of Bioceramic Materials Used in the Dentin-Pulp Complex Therapy: A Systematic Review. Materials (Basel) 2019;12:1015. doi:10.3390/ma12071015.

[39] Ricucci D, Loghin S, Lin LM, Spångberg LSW, Tay FR. Is hard tissue formation in the dental pulp after the death of the primary odontoblasts a regenerative or a reparative process? J Dent 2014;42:1156-70. doi:10.1016/j.jdent.2014.06.012.

[40] Yonehiro J, Yoshida Y, Yamashita A, Yoshizawa S, Ohta K, Kamata N, et al. Flavonolcontaining phosphorylated pullulan may attenuate pulp inflammation. Int Endod J 2013;46:119-27. doi:10.1111/j.1365-2591.2012.02095.x.

[41] Fitzgerald M. Cellular Mechanics of Dentinal Bridge Repair Using 3H-Thymidine. J Dent Res 1979;58:2198-206. doi:10.1177/002203457905800411011.

[42] Gronthos S, Mankani M, Brahim J, Robey PG, Shi S. Postnatal human dental pulp stem cells (DPSCS) in vitro and in vivo. Proc Natl Acad Sci U S A 2000;97:13625-30. doi:10.1073/pnas.240309797.

[43] Adams GB, Chabner KT, Alley IR, Olson DP, Szczepiorkowski ZM, Poznansky MC, et al. Stem cell engraftment at the endosteal niche is specified by the calcium-sensing 
receptor. Nature 2006;439:599-603. doi:10.1038/nature04247.

[44] Bunpetch V, Zhang X, Li T, Lin J, Maswikiti EP, Wu Y, et al. Silicate-based bioceramic scaffolds for dual-lineage regeneration of osteochondral defect. Biomaterials 2019;192:323-33. doi:10.1016/j.biomaterials.2018.11.025.

[45] Valerio P, Pereira M, Goes A, MF L. The effect of ionic products from bioactive glass dissolution on osteoblast proliferation and collagen production. Biomaterials $2004 ; 25: 29$ 


\section{biominal.}

Table 1. List of hydraulic calcium-silicate cements (hCSCs) investigated and their application mode.

\begin{tabular}{|c|c|c|c|}
\hline $\begin{array}{l}\text { Product } \\
\text { (company) }\end{array}$ & POWDER (wt\%) & LIQUID & Application mode \\
\hline $\begin{array}{l}\text { PPL_hCSC } \\
\text { (GC, Tokyo, Japan) }\end{array}$ & $\begin{array}{l}\text { Portland cement }(60 \%) \\
\text { Bismuth oxide }(20 \%) \\
\text { Calcium sulfate dehydrate }(5 \%) \\
\text { PPL }(5 \%) \\
\text { Other }(10 \%)\end{array}$ & Distilled water & $\begin{array}{l}\text { Shake the capsule by hand and activate. } \\
\text { Mix for } 10 \text { sec. }\end{array}$ \\
\hline $\begin{array}{l}\text { Biodentine } \\
\text { (Septodont, Saint Maur } \\
\text { des Fossés, France) }\end{array}$ & $\begin{array}{l}\text { Tricalcium silicate }(80 \%) \\
\text { Calcium carbonate }(15 \%) \\
\text { Zirconium oxide }(5 \%)\end{array}$ & $\begin{array}{l}\text { Calcium chloride } \\
\text { Water soluble polymer }\end{array}$ & $\begin{array}{l}\text { Add 5-6 drops of liquid inside the capsule. } \\
\text { Mix for } 30 \mathrm{sec} \text {. }\end{array}$ \\
\hline
\end{tabular}

$P P L=$ Phosphopullulan 
Table 2. Mineral foci formation around the pulp-exposure area.

\begin{tabular}{|c|c|c|}
\hline \multirow{2}{*}{ Pulp-capping agent } & \multicolumn{2}{|c|}{4 wk pulp capping in human tooth-culture model } \\
\hline & Teeth total $(n)$ & Mineral foci formed (tooth number) \\
\hline PPL_hCSC & 3 & $3(100 \%)$ \\
\hline Biodentine & 3 & $3(100 \%)$ \\
\hline Control (exposure without capping agent) & 3 & $0(0 \%)^{*}$ \\
\hline
\end{tabular}

* Indicates statistically significant difference $(p<0.05)$. 
Table 3. The continuity of mineralized tissue in exposed pulps capped with the two hCSCs for 70 days.

\begin{tabular}{rccc}
\hline \multirow{2}{*}{ Pulp-capping agent } & \multicolumn{3}{c}{ Presence and type of mineralized tissue in \% } \\
\cline { 2 - 4 } & None & Partial & Complete \\
\hline PPL_hCSC & 0 & 0 & 100.0 \\
Biodentine & 0 & 0 & 100.0 \\
\hline
\end{tabular}

No significant difference was detected among the pulp-capping agents investigated ( $p>0.05)$. 
Table 4. The occurrence rate of inflammatory response in exposed pulps capped with the two hCSCs for 7 days and the corresponding inflammatory grade.

\begin{tabular}{rcccccc}
\hline \multirow{2}{*}{ Pulp-capping agent } & \multicolumn{5}{c}{ Inflammatory grade (n) } \\
\cline { 2 - 6 } & Grade 0 & Grade 1 & Grade 2 & Grade 3 & Grade 4 \\
\hline PPL_hCSC & 0 & 5 & 6 & 1 & 0 \\
Biodentine & 1 & 5 & 2 & 0 & 0 \\
\hline
\end{tabular}

No significant difference was detected in the occurrence of inflammation among the pulp-capping agents investigated ( $p>0.05)$. 
Table 5. The nature of the mineralized tissue formed in exposed pulps capped by the two hCSCs for 70 days.

\begin{tabular}{rccc}
\hline \multirow{2}{*}{ Pulp-capping agent } & \multicolumn{2}{c}{ Osteodentin bridge maturation after 70 days (n) } \\
\cline { 2 - 4 } & Immature & Maturing & Mature \\
\hline PPL_hCSC & 0 & $9(75 \%)$ & $3(25 \%)$ \\
Biodentine & 0 & $6(75 \%)$ & $2(25 \%)$ \\
\hline
\end{tabular}

No significant difference was detected among the pulp-capping agents investigated ( $p>0.05)$. 


\section{FIGURE LEGENDS}

Figure 1. Molecular structure of phosphorylated pullulan present in the composition of PPL_hCSC.

Figure 2. Pulp-tissue reaction of three representative teeth after 4 wk in the human tooth-culture model, with histological micrographs of pulps that were capped by PPL_hCSC $(G C)$ in $(\mathbf{a}, \mathbf{b})$ and Biodentine (Septodont) in (c,d), or were kept without capping material (control) in (e,f). (a) Overview micrograph showing remnants of PPL_hCSC (GC) above the exposure site. An amorphous, eosinophilic layer was detected underneath the capped area. Beneath this layer, many mineral foci were observed in the pulp tissue adjacent to the exposure site. (b) Higher magnification of the rectangle in (a), identifying accumulation of 20-50 $\mu \mathrm{m}$ mineral foci within the pulp tissue next to the capped site (hand pointers). (c) Overview micrograph revealing remnants of Biodentine (Septodont) above the pulpexposure site. The exposed pulp tissue was well structured with a 50-100 $\mu \mathrm{m}$ band of fibrinous hyalinized tissue delineating the whole exposure area. Beneath the fibrinous band, multiple mineral foci can be seen. (d) Higher magnification of the rectangle in (c), showing the presence of many mineral foci surrounding the exposure area (hand pointers). (e) Overview micrograph of the pulp exposure that remained uncapped (control). The pulp tissue remained well organized and exhibited common histological features. (f) Higher magnification of the rectangle in (e) did not reveal any inflammatory reaction in the pulp tissue around the exposure area. No mineral foci, nor fibrinous tissue reaction was observed. (D: dentin; hCSC: hydraulic calcium-silicate cement; P: pulp tissue).

Figure 3. Reconstructed micro-CT $(\mu \mathrm{CT})$ images and corresponding histological micrographs of teeth capped for 7 days by PPL_hCSC (GC) in (a-d) and by Biodentine (Septodont) in (e-h) (minipig animal experimentation). (a) $\mu \mathrm{CT}$ scan of the tooth capped by PPL_hCSC showing a radiodensity increase for the pulp tissue underneath the exposure (arrow). (b) Histological micrograph of the same tooth as in (a), revealing that the pulp tissue underneath the exposure stained more intensely than the deeper pulp tissue. (c) Higher magnification of the rectangle in (b), detailing the more intensely stained pulp tissue with a denser network of collagen fibers. (d) Higher magnification of the rectangle in (c), revealing a layer of amorphous fibrinous tissue in contact with the hCSC. Below, an area of loose, smooth connective tissue was observed (inflammation degree 1 was scored for this specimen). (e) $\mu C T$ scan of the tooth capped by Biodentine (Septodont), disclosing an obvious change in radiodensity for the exposed pulp (arrows). (f) Histological micrograph of the same tooth, presenting a normal pulp histology. A thin bundle of eosinophilic, hyalinized tissue can be seen in the contact area between the pulp-capping material and pulp tissue. (g) Close-up view of the white rectangle in (f), depicting the area close to the pulp capping (approximately $500 \mu \mathrm{m}$ from the exposure site) with the presence of some dilated blood vessels and eosinophilic granules (pointers). (h) Higher magnification of the white square in $(\mathrm{g})$, showing dilated blood vessels and round eosinophilic granules that seem to be associated with 
eosinophilic granulocites (pointers). Beneath this area, a less eosinophilic zone of smooth connective tissue is depicted (inflammation degree 2 was scored for this specimen). (D: dentin; hCSC: hydraulic calciumsilicate cement; P: pulp tissue).

Figure 4. Three-dimensional $\mu C T$ reconstruction of two teeth capped for 70 days by PPL_hCSC (GC) in (a-c) and by Biodentine (Septodont) in (d-f) (minipig animal experimentation). The 3D reconstructions revealed thick osteodentin bridges completely covering the pulp-exposure areas. Inside the bridge, clear pores were detected, however without direct contact between hCSC and pulp (tunnel defects). The white horizontal lines in (b) and (e) indicate the position depicted by the axial plane.

Figure 5. Inflammatory reaction of two teeth capped for 7 days by PPL_hCSC (GC) in (a-c) and by Biodentine (Septodont) in (d-f) (minipig animal experimentation). (a) Overview micrograph of the PPL_hCSC-capped tooth, revealing that the coronal pulp was exposed, while the underlying pulp tissue remained well organized. An eosinophilic debris layer was observed underneath the exposure site. Beneath this amorphous tissue bundle, an intense eosinophilic layer of stromal cells was disclosed. (b) Higher magnification of the rectangle in (a), showing accumulation of cells within the pulp tissue near to the exposed area. Deeper in the pulp, the pulp tissue was free of inflammatory cells and exhibited a normal histological appearance. (c) Higher magnification of the rectangle in (b), disclosing prominent vascular vessels (hand pointer). (d) Overview micrograph of the Biodentine-capped tooth, revealing remnants of the hCSC pulp-capping agent above the exposure site. The exposed pulp tissue was well structured; the gaps/holes within the pulp in the root canals should be regarded as tissue-processing artefacts. (e) Higher magnification of the rectangle in (d), revealing the presence of many mineral foci surrounding the exposure area. (f) Higher magnification of the rectangle in (e), detailing the mineral foci (hand pointer). In a deeper area away from the exposure site, pulp tissue with a normal histological appearance was observed (D: dentin; hCSC: hydraulic calcium-silicate cement; P: pulp tissue).

Figure 6. Inflammatory reaction of a tooth capped for 7 days using PPL-hCSC (GC) in (a-b) and a representative control tooth extracted at the end of the 70-day experimentation time (c-e) (minipig animal study). (a) Overview of the tooth capped with PPL_hCSC, showing exposure of the pulp chamber with intact remaining pulp tissue adjacent to it. An intense eosinophilic staining is shown next to the exposed area. (b) Zoom-in view of the black circle in (a). Higher magnification of the area next to the exposure site $(300-500 \mu \mathrm{m})$ revealing dilated vascular vessels. This, together with the presence of groups of eosinophilic granules [pointers in (b), which may be compatible with eosinophilic granulocytes] indicate a moderate inflammatory reaction (ISO inflammatory grade 2 was given to this sample). The area located a bit further from the exposure site shows the presence of some dilated blood vessels within a normal pulp-tissue architecture. (c) Representative micrograph of a control 
tooth (no exposure and no capping). (d) Higher magnification of the upper black rectangle in (c), showing a classical image of healthy pulp tissue composed of loose connective tissue. No eosinophilic granules or any other inflammatory cells can be seen. A palisade of odontoblasts lining the dentin on both sides of the pulp tissue is depicted. (e) Higher magnification of the lower black rectangle in (c) showing the presence of some dilated vessels. The presence of scattered dilated vessels does not necessarily indicate unhealthy pulp tissue but is rather a common finding. Notice the absence of eosinophilic granules or any other organelles compatible with inflammatory cells extravasated next to the blood vessels.

Figure 7. Reparative dentin formation of two teeth capped for 70 days by PPL_hCSC (GC) in (a-c) and by Biodentine (Septodont) in (d-e) (minipig animal experimentation). (a) Overview micrograph of the PPL_hCSC-capped tooth, showing hCSC remnants above the exposure site. The pulp exposure was completely sealed by a layer of mineralized tissue with a thickness of approximately $250-750 \mu \mathrm{m}$. A disorganized pattern of mineralization was observed in the upper part of the bridge (near to the hCSC). (b) Higher magnification of the white rectangle in (a), disclosing a well-organized pattern of a maturing dentin bridge $(*)$ beneath the irregular mineral layer. (c) Higher magnification of the white circle in (a), revealing a well-organized pulpal tissue with a palisade of odontoblast-like cells surrounding the bridge (pointer). (d) Overview micrograph of a Biodentine-capped tooth, indicating that the pulp exposure was completely sealed by a layer of mineralized tissue with a thickness of approximately $200-400 \mu \mathrm{m}$. A first layer of fibrinous, compacted, necrotic tissue was seen in the upper part of the bridge in contact with the hCSC. (e) Higher magnification of the white rectangle in (d), disclosing a thick disorganized mineralized bridge beneath the necrotic layer. Underneath, a bridge structure containing dentin tubules was revealed $\left({ }^{*}\right)$. (D: dentin; hCSC: hydraulic calcium-silicate cement; P: pulp tissue; RD: reparative dentin). 
Figure 1

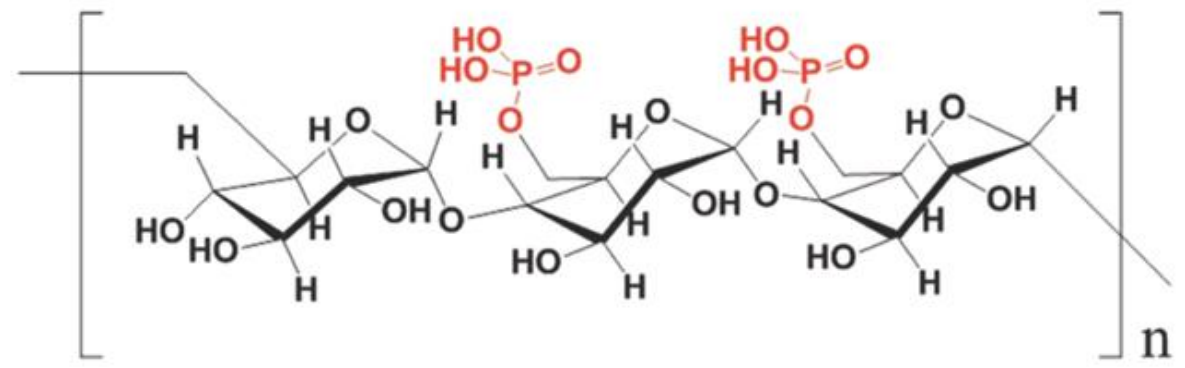


Figure 2
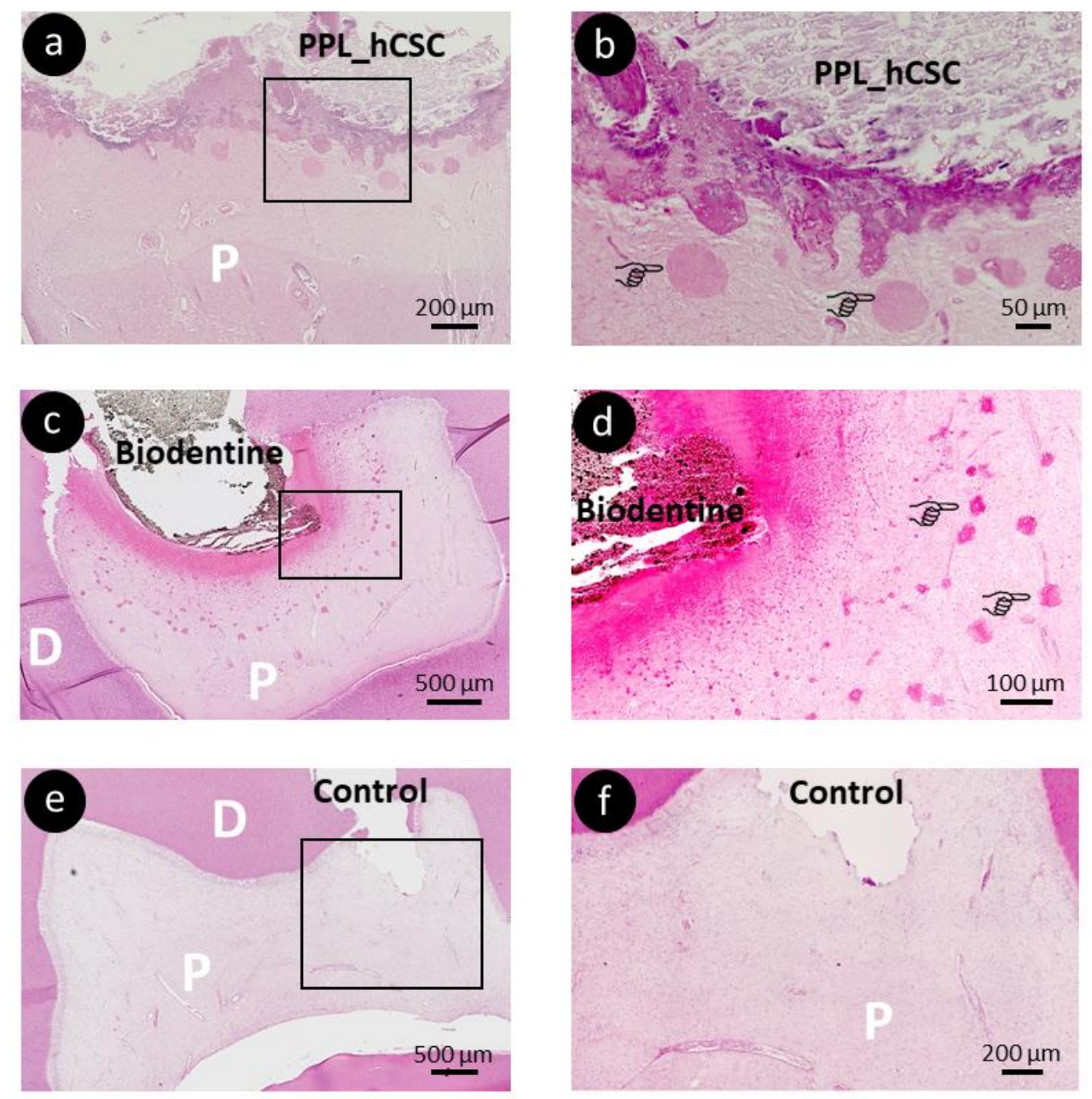


\section{bionnal.}

Figure 3
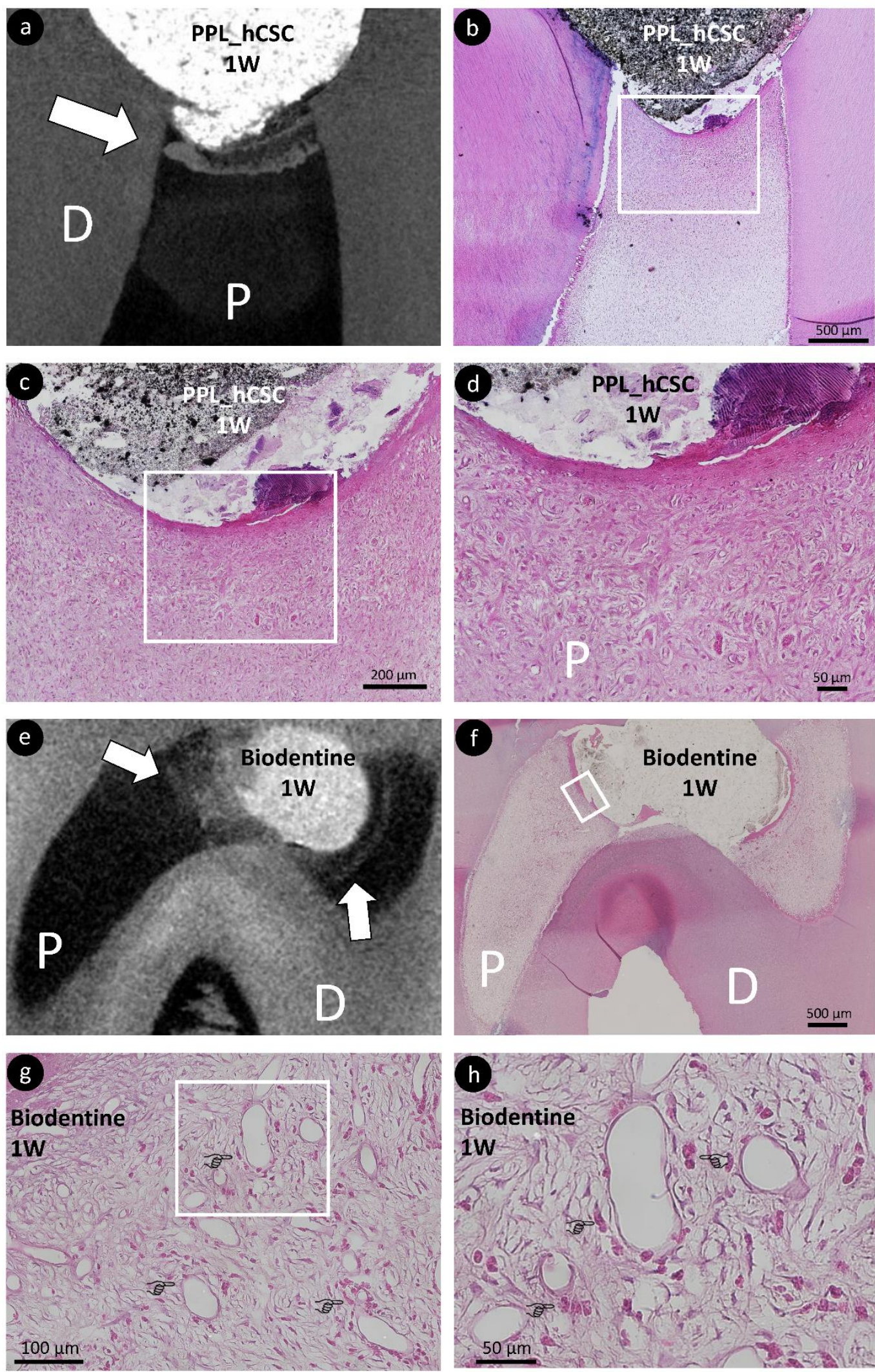


\section{bionnal.}

Figure 4
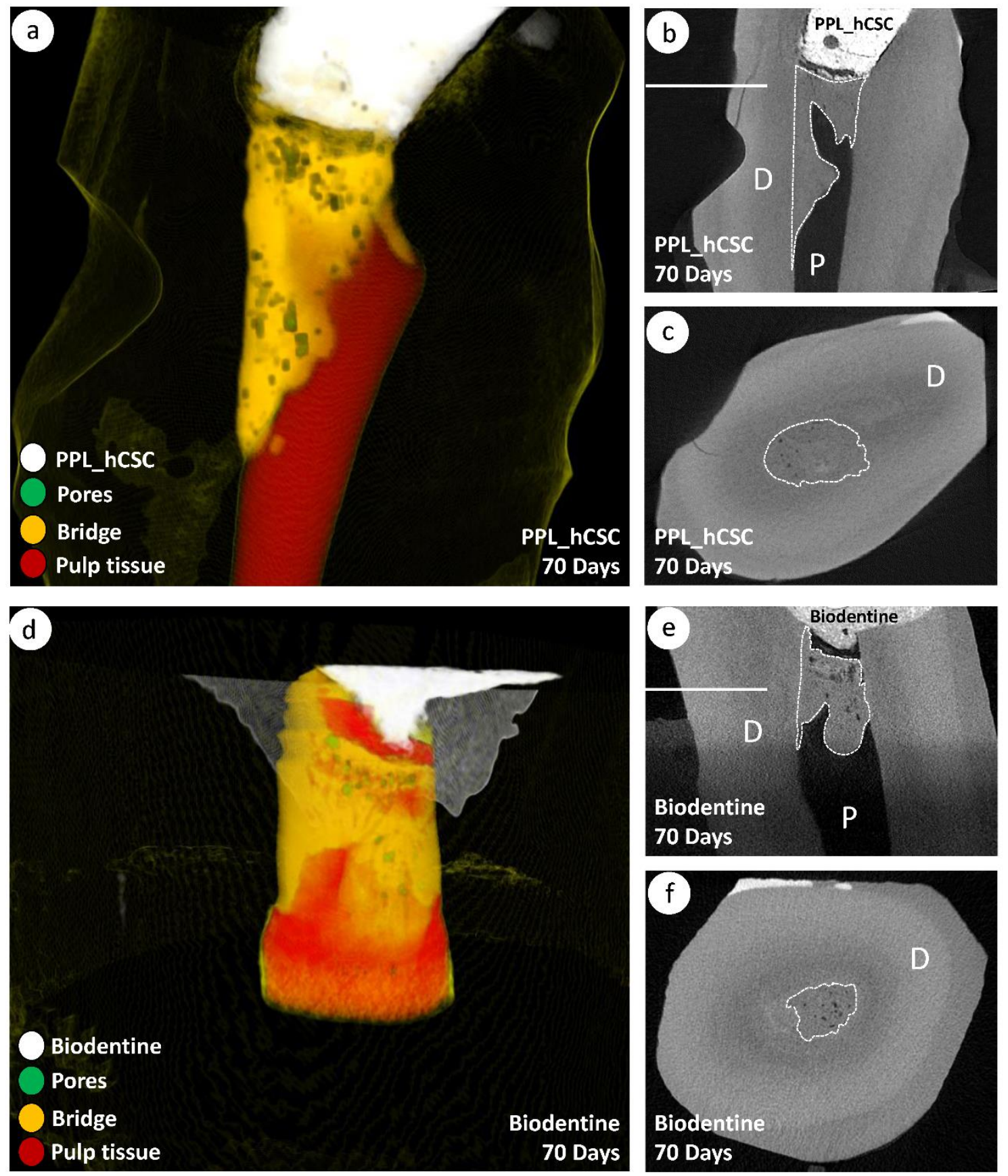
Figure 5
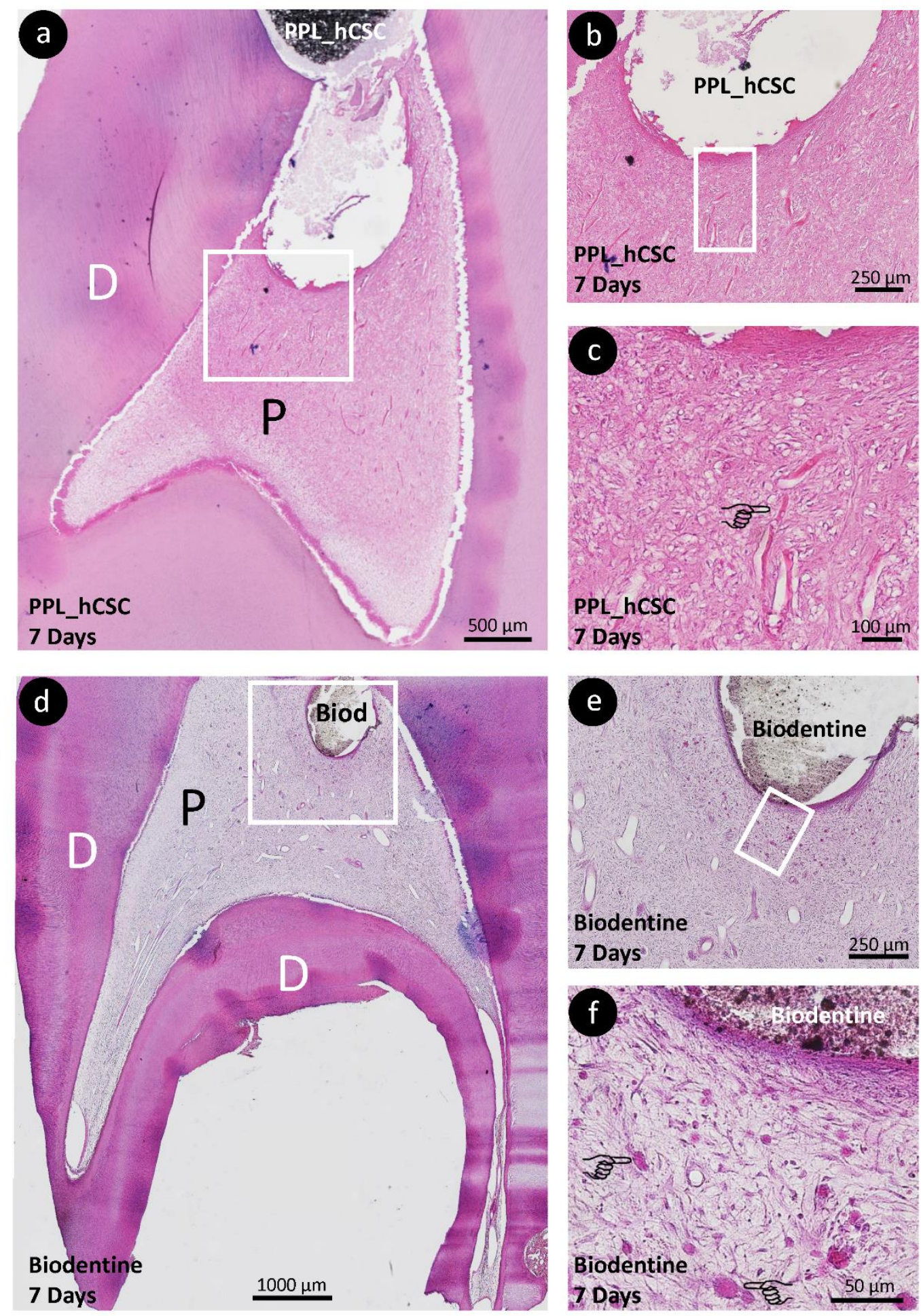


\section{bionnal.}

Figure 6
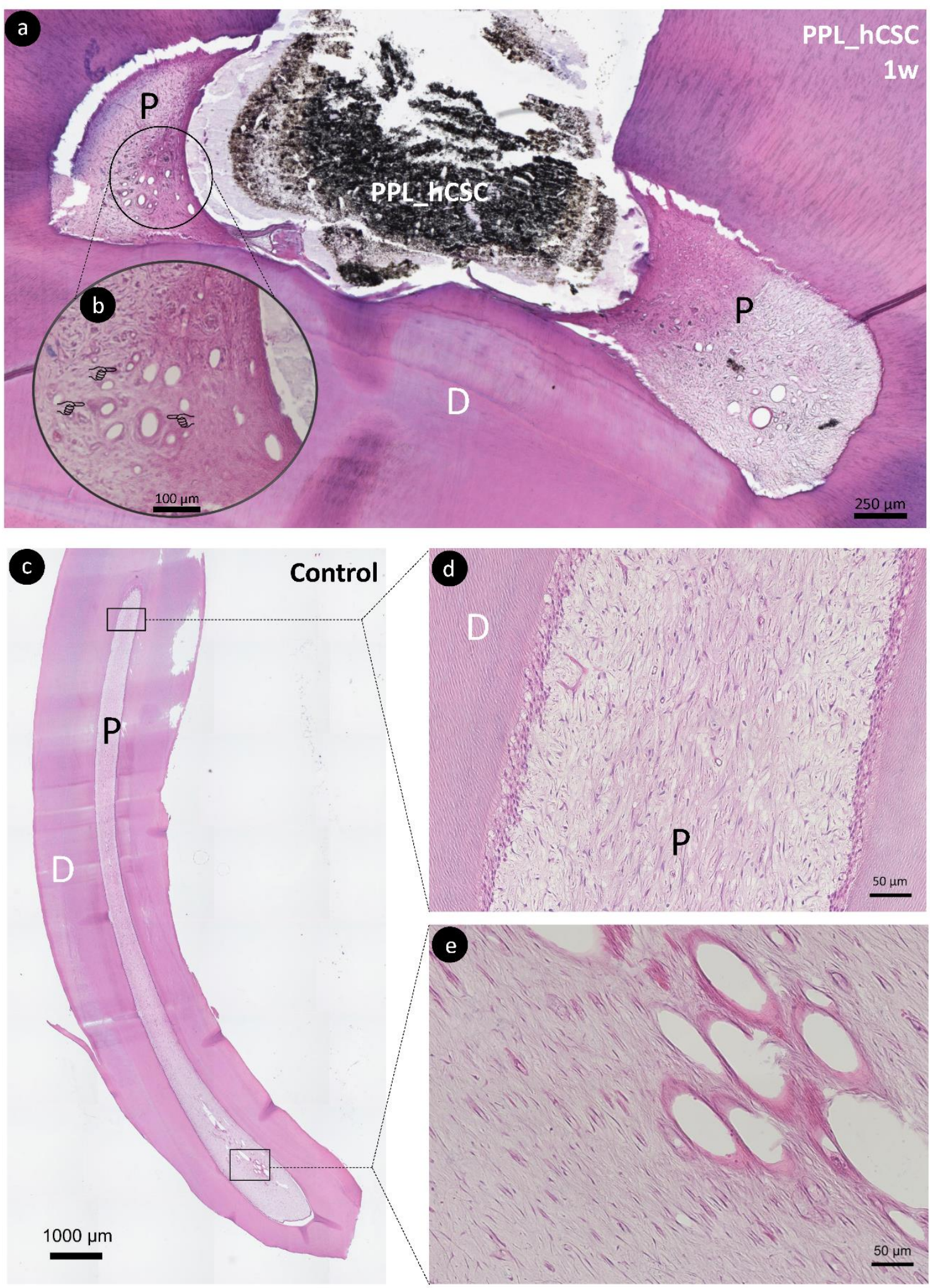


\section{biolneale}

Figure 7
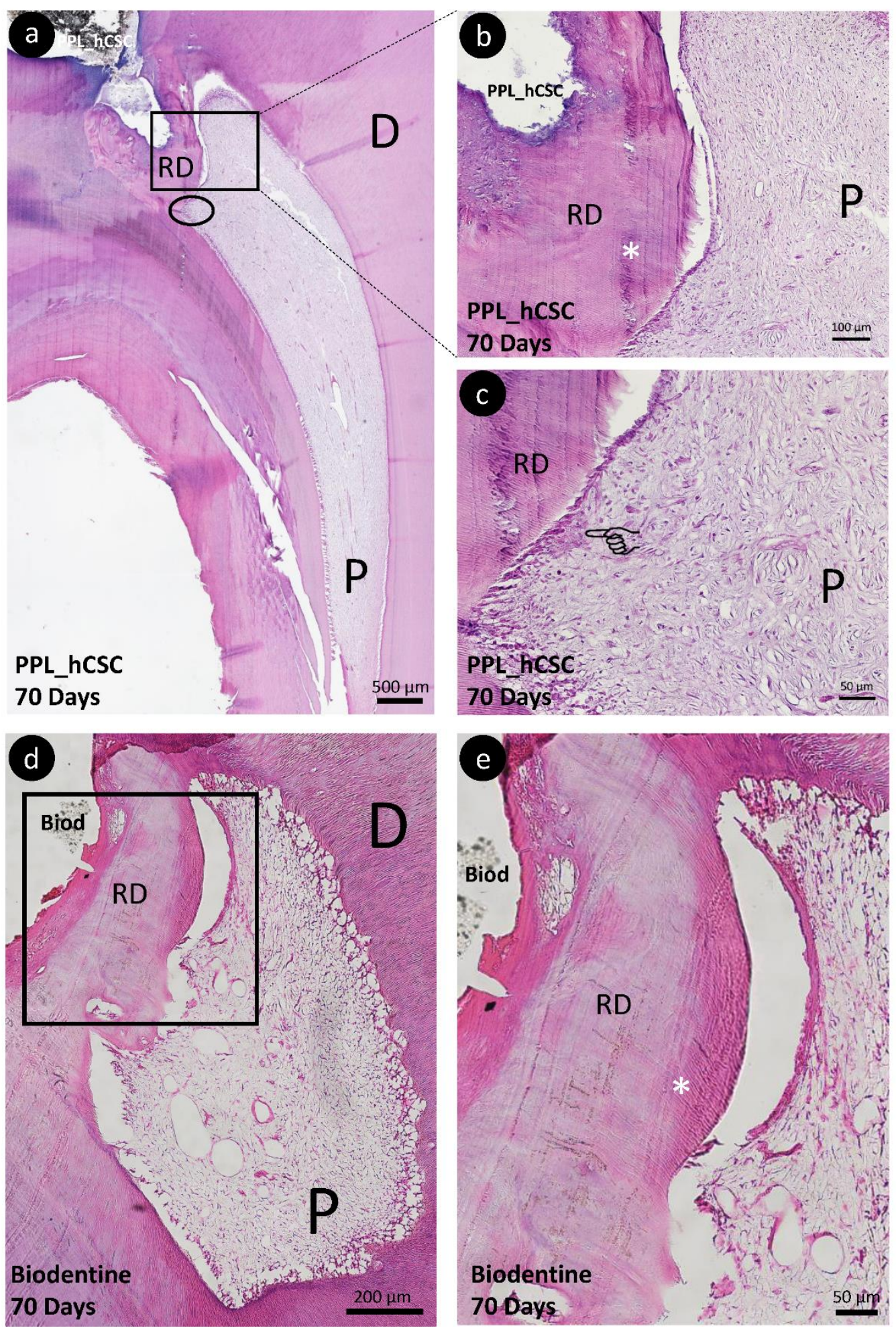